\title{
ESTUDO COMPARATIVO ENTRE O SISTEMA DE GESTÃO AMBIENTAL DO EXÉRCITO BRASILEIRO E A NORMA ISO 14001
}

\section{Eduardo Borba Neves}

Doutor em Engenharia Biomédica (COPPE/UFRJ) - Professor do Centro Universitário UNIANDRADE - Curitiba - PR. E-mail: borbaneves@hotmail.com

\section{Brani Rozemberg}

Doutora em Saúde Pública (FIOCRUZ) - Pesquisadora Titular da Fundação Oswaldo Cruz - Rio de Janeiro - RJ.

\section{Resumo}

Este estudo descreve a evolução do sistema de gestão ambiental do Exército Brasileiro (SiGAEB), discutindo seus pontos em comum com as orientações previstas na norma NBR ISO 14001:2004 e suas peculiaridades. Foi realizado por meio de análise da Norma e dos documentos institucionais relativos à gestão ambiental emitidos no período de novembro de 2001 à dezembro de 2008. Os resultados indicam que o SiGAEB foi planejado de acordo com as fases preconizadas pela NBR ISO 14001, ainda que com uma série de aspectos ausentes e um foco das autoridades militares ainda muitas vezes restrito ao atendimento aos requisitos legais à realização de obras, distanciando-se do proposto pela Norma. Vimos ainda que a cultura militar apresenta elementos que podem favorecer a operação do sistema da gestão ambiental, tais como: a prática da inspeção regular; a formação e a experiência militares na realização de registros; e as atividades de rotina das organizações militares que preconizam cuidados para não deixar vestígios no ambiente, entre outros. Outro aspecto a ser destacado é a necessidade de se superar a atual precariedade da comunicação interna sobre a área de gestão ambiental, no interior instituição.

Palavras-chave: gestão ambiental; exército; ISO 14001; ambiente; normas

\begin{abstract}
This study describes the development of the environmental management system of the Brazilian Army (SiGAEB), arguing their points in common with the guidelines provided in the standard NBR ISO 14001:2004 and its peculiarities. It was performed through the analysis of standard and institutional documents related to environmental management, issued between November 2001 to December 2008. The results indicate that SiGAEB was planned according to the phases recommended by ISO 14001, though with a number of aspects missing and the focus of the military authorities, often restricted to meeting the legal requirements to perform work, despite of what is proposed by the Standard. We have also seen that the military culture has elements that would favor the operation of the system of environmental management, such as the practice of regular inspection, training and experience in the conduct of military records, and the routine activities of military organizations which prevents environmental

\footnotetext{
${ }^{1}$ Recebido em 01.11.2009. Aprovado em 19.03.2010. Disponibilizado em 28.04.2010. Avaliado pelo sistema double blind review
} 
impacts. Another aspect to be highlighted is the need to overcome the current weakness of the internal communication on the area of environmental management within the institution.

Keywords: environmental management; army; ISO 14001; environment; standard

\section{INTRODUÇÃO}

O intenso processo de degradação do meio ambiente e dos recursos naturais tem elevado a temática ambiental ao primeiro plano das prioridades globais (Souza, 2000). Tratando-se então de um "desafio para a comunidade científica, para os agentes do setor público e para a sociedade civil organizada” (Andrade Júnior, 2005).

Essa temática emergiu em torno dos anos 70 do século XX como problema significativo a nível mundial expressando um conjunto de contradições que, engendradas pelo desenvolvimento técnico-científico e pela exploração econômica, se revelou na degradação dos ecossistemas e na qualidade de vida das populações, levantando, inclusive, ameaças à continuidade da vida no longo prazo (Lima, 1999).

No Brasil, o meio ambiente surgiu como política pública não pontual após a Conferência de Estocolmo, em 1972, quando, devido às iniciativas das Nações Unidas em inserir o tema nas agendas dos governos (Sorrentino, 2005), foi criada a Secretaria Especial de Meio Ambiente (SEMA) por meio do Decreto 73.030, de 30 de outubro de 1973, como um órgão autônomo da Administração Direta no âmbito do Ministério do Interior, orientada para a conservação do meio ambiente e uso racional dos recursos naturais.

Por outro lado, o pensamento político e econômico que vigia no país, nessa década, era a do crescimento econômico a qualquer custo. Nessa época o dilema "poluição X crescimento econômico" tinha como opção certa o crescimento econômico. Os militares estavam no governo, e o Brasil tinha que se projetar no cenário econômico mundial (Dias e Aguirre, 1992).

Os militares conduzem um vasto leque de atividades que, em muitos aspectos, podem se assemelhar as empresas ou indústrias do setor privado tais como: Utilização de veículos comerciais, construção de prédios e urbanização de espaços, entre outras. Por outro lado, este segmento profissional desenvolve atividades especificamente militares, tais como: desenvolvimento e uso de armas de combate e treinamento da tropa para a guerra regular (United States Department of Defense and Swedish Armed Force, 1999). Devido ao potencial de danos associado a suas atividades, o exército se inclui entre as instituições que requerem alta confiabilidade organizacional (Roberts et al 1994)

O desenvolvimento de metodologias acuradas para estimar impactos das atividades especificamente militares sobre ecossistemas terrestres e aquáticos (Michael et al 2003) favorece a ampla documentação ambiental e contribui na identificação de espécies ameaçadas ou em risco de extinção (Diersing et al 1992) e mais recentemente vem ocorrendo o refinamento de análises cumulativas do impacto da atividade de treinamento militar sobre o ambiente (Wang,2009)

Agindo no ambiente de forma responsável, o setor militar apresenta potencial para exercer um exemplo significativo à sociedade. O exército responde pela gestão de grandes áreas de terras, opera instalações industriais, realiza ações subsidiárias junto aos cidadãos brasileiros e responde por mais de 300.000 homens e mulheres organizados sob seus postos e graduações, todos sob a liderança suprema do Presidente da República. Assim, o Exército Brasileiro possui um grande potencial para prejudicar ou beneficiar o ambiente de forma significativa. 
Coerente com essa tendência mundial, e com o contido no Art. 225ํㅜ da Constituição da República Federativa do Brasil de 1988, que impõe ao Poder Público (neste contido o Exército Brasileiro) e à coletividade o dever de defender e preservar o meio ambiente para as gerações presentes e futuras (Brasil, 1999), o Exército Brasileiro, por intermédio da portaria $\mathrm{n}^{\circ}$ 570, de 6 de novembro de 2001, estabeleceu a Política de Gestão Ambiental da Força Terrestre (PGAEB) (Brasil, 2001a).

Na mesma data, estabeleceu na portaria $n^{0} 571$ a Diretriz Estratégica de Gestão Ambiental do Exército (DEGAEB), com a finalidade de orientar a gestão ambiental do Exército Brasileiro, que em sua primeira premissa básica ressalta a importância da gestão ambiental em todas as atividades da instituição (Brasil, 2001b).

O anexo H das DEGAEB trás a constituição do Sistema de Gestão Ambiental do Exército Brasileiro e prevê ainda que suas ações devam estar em consonância com a doutrina militar terrestre e com a Política Nacional de Meio Ambiente (PNMA). Assim, esse sistema de gestão surge com o propósito de encontrar um sinergismo entre as atividades de preparo e emprego da tropa e a proteção ambiental.

Em nível internacional, podem-se observar algumas experiências e estudos de casos que indicam que países como Canadá, Espanha, Suécia, o Reino Unido e os Estados Unidos já têm bons exemplos de integração de práticas ambientais no setor militar: controle do ruído, reciclagem e compostagem dos resíduos, tratamento de águas residuais, gestão da utilização e descontaminação dos solos, conservação dos ecossistemas e educação ambiental (Nato, 2000; Usaf,1995; Patterson, 1999; Lederer, 1997; Land Force Command et al., 1999; Denix, 2007).

Para compreendermos a Política de Gestão Ambiental do Exército é preciso ter clara a definição do que é um Sistema de Gestão Ambiental. Segundo a United States Environmental Protection Agency (USEPA), um Sistema de Gestão Ambiental (SGA) é um conjunto de processos e práticas que permitam uma organização a reduzir seus impactos ambientais e aumentar a sua eficiência operacional (USEPA, 2008). Coerente com esse conceito, a International Standardzation for Organization (ISO) publicou uma série de normas (série ISO 14000) que colocam à disposição dos usuários, orientações à organização e implementação de um Sistema de Gestão Ambiental. No Brasil, toda a série de normas ISO vem precedida da designação NBR, que significa Norma Brasileira de Regulamentação.

Este conjunto de normas, quando corretamente implementadas, auxiliam as instituições a atender a legislação ambiental aplicável, considerar todos os aspectos do seu processo produtivo que possam causar impactos ao ambiente e a buscar continuamente a melhoria nos resultados obtidos, através do monitoramento, auditoria do sistema e de sua análise crítica (Luigi,1999).

Países como Portugal, Canadá, Espanha e particularmente os Estados Unidos da América (EUA) estão se valendo de Sistemas de Gestão Ambiental (SGA) orientados com referência nas normas ISO 14001 (Portugal, 2008; Espanha, 2008; Land Force Command et al., 1999; USEAC, 2007). O exército Norte Americano já possui 50 instalações certificadas pela norma ISO 14001 e pretendem certificar outras tantas até 30 de setembro de 2009 (Denix, 2007).

O Exército Brasileiro possui sobre sua tutela cerca de $22.000 \mathrm{~km}^{2}$ de área, distribuídos por todo território brasileiro. Ao compararmos esta área com o tamanho dos Estados da Federação, verificaremos que esta é maior que o estado de Sergipe. Estas áreas são capazes de representar todos os biomas do Brasil, pois é possível encontrar Unidades do EB localizados nos Campos Sulinos, Cerrado, Floresta Equatorial, Mata Atlântica, regiões de Dunas e no Sertão Nordestino (Abreu, 2006).

É preciso destacar que, anualmente, instruções militares são realizadas em Campos de Instrução (CI), normalmente áreas verdes, consideradas apropriadas ao emprego de tropa e 
também ao tiro de armas de fogo de grosso calibre, onde se procura simular o combate real. Nessas atividades, as ações antrópicas causam danos ambientais (Abreu, 2006).

Considerando a experiência internacional e as peculiaridades do Exército Brasileiro surgem indagações: Como se deu a implantação do Sistema de Gestão Ambiental do Exército Brasileiro (SiGAEB), e como está funcionando atualmente? Quais os pontos em comum e as peculiaridades desse sistema com relação às orientações previstas na norma NBR ISO 14001:2004? Assim, o presente estudo tem por objetivo descrever a evolução do sistema de gestão ambiental do Exército Brasileiro (SiGAEB), discutindo seus pontos em comum com as orientações previstas na série de normas NBR ISO 14001:2004 e suas peculiaridades.

Em sua concepção, a série de Normas NBR ISO 14001 tem como objetivo central um sistema de gestão ambiental que auxilia as instituições a programar práticas que a possibilitem operar com responsabilidade ambiental. Como objetivos decorrentes, a norma cria os sistemas de certificação, tanto para as empresas como para seus produtos e processos, possibilitando assim distinguir as organizações que atendem à legislação ambiental e as que cumprem os princípios do desenvolvimento sustentável (Cagnin, 2000).

O presente texto se propõe a analisar as peculiaridades da participação do Exército Brasileiro nessa complexa temática, tendo como eixo de análise as normas NBR ISO 14001.

\section{METODOLOGIA}

O estudo foi realizado por meio de análise da NBR ISO 14001:2004 e dos documentos institucionais relativos à gestão ambiental no âmbito do Exército Brasileiro emitidos no período de novembro de 2001 a dezembro de 2008. Escolheu-se esse período, pois a publicação da Política de Gestão Ambiental do Exército Brasileiro (PGAEB) se deu no início desse período, e a análise final dos documentos aconteceu em dezembro de 2008.

Inicialmente foi realizado o estudo da NBR ISO 14001:2004, que neste trabalho será considerada a referência para análise e discussão do Sistema de Gestão Ambiental do Exército Brasileiro (SIGAEB). Com relação aos demais documentos, após consulta prévia realizada às autoridades da área de meio ambiente do Exército, foi indicado um endereço eletrônico, de acesso livre, que compõe o site oficial da Força Terrestre, no qual são disponibilizadas leis, portarias, normas e instruções reguladoras sobre os diversos temas de interesse da instituição. Neste site foram coletados os documentos emitidos pelo Exército no período entre 2001 e 2008.

Para a análise dos documentos obtidos foi utilizada a técnica análise de conteúdo. Segundo Laville \& Dionne (1999), a análise de conteúdo é principalmente aplicada nos dados que se apresentam como texto e apresenta três etapas para o processo: a etapa do recorte dos conteúdos; a definição das categorias analíticas; e a categorização final das unidades de análise.

Neste estudo optou-se por utilizar as cinco fases de estruturação de um SGA propostas pela NBR ISO 14001:2004 como categorias pré-definidas à análise dos dados. Estas fases são caracterizadas da seguinte forma:

1. Compromisso com uma Política Ambiental: nessa fase, a organização, por meio da alta administração, define uma política ambiental e assegura o seu comprometimento com ela;

2. Planejamento: a organização formula um plano que satisfaça as políticas definidas, considerando, na definição de seus objetivos e metas ambientais, os aspectos relacionados aos impactos significativos de suas atividades, e também garante os recursos físicos e financeiros para a sua implementação; 
3. Implementação e Operação: a organização expõe um plano em ação, fornecendo os recursos e mecanismos de apoio e definindo funções, responsabilidades e autoridades relativas a controle de documentos, controle operacional e preparação e resposta à emergências;

4. Verificação e Ação Corretiva: a organização mede, monitora e avalia periodicamente o seu desempenho ambiental, realiza auditorias internas e uma avaliação do controle de registros;

5. Análise Crítica e Melhoria: a organização, por meio da alta administração e em intervalos periódicos por ela predeterminados, realiza uma análise crítica e implementa melhorias em seu SGA, para alcançar o desempenho ambiental desejado.

Cada uma dessas fases possui subitens (apresentados na Figura 1) que detalham as exigências de padronização do SGA. Assim, os conteúdos foram recortados e alocados diretamente em uma das cinco categorias estabelecidas. Esse procedimento teve por objetivo facilitar a comparação entre a Norma e o SiGAEB, permitindo ainda, a referencia a conteúdos específicos do SiGAEB classificando-os como peculiaridades da Instituição.

\section{RESULTADOS}

Para o entendimento da discussão proposta, torna-se necessário normalizar o entendimento sobre a proposta da NBR ISO 14001:2004 e da cronologia de implantação do Sistema de Gestão Ambiental do Exército Brasileiro.

\section{O Sistema de Gestão Ambiental preconizado pela NBR ISO 14001:2004}

A ISO é uma organização não-governamental fundada em 1947, com sede em Genebra, Suíça. O representante brasileiro na ISO, que congrega órgãos de mais de cem países, é a ABNT (Associação Brasileira de Normas Técnicas). A ISO busca normas de homogeneização de procedimentos, de medidas, de materiais e/ou de uso que reflitam o consenso internacional em todos os domínios de atividades, exceto no campo eletroeletrônico que é de atribuição da IEC (International Electrotechnical Commission) (Maimon, 1999).

Como vimos, em sua concepção, um sistema de gestão ambiental auxilia as instituições a programar práticas que a possibilitem operar com responsabilidade ambiental. Como objetivos decorrentes, a norma NBR ISO 14001:2004, cria os sistemas de certificação, tanto para as empresas como para seus produtos e processos, possibilitando assim distinguir as organizações que atendem à legislação ambiental e as que cumprem os princípios do desenvolvimento sustentável (Cagnin, 2000).

Segundo Seiffert (2005), suas características mais importantes são: a pró-atividade: seu foco é na ação e no pensamento pró-ativo, em lugar da reação a diretrizes passadas; e $a$ abrangência: envolve todos os membros da organização ligados direta e indiretamente, podendo ser implementada em qualquer organização independentemente de sua atuação.

Essa Norma é importante no sentido de que reforça o enfoque no aprimoramento da conservação ambiental pelo uso de um único sistema de gerenciamento que permea todas as funções da organização. A NBR ISO 14001:2004 não estabelece padrões de desempenho ambiental absoluto, mas torna as organizações mais aptas a gerenciarem as questões do meio ambiente, tendo em vista as necessidades de adaptarem-se as pressões externas (Santos, 2007).

A NBR ISO 14001:2004 prevê os passos de implementação do Sistema de Gestão Ambiental partindo de uma metodologia conhecida como Plan-Do-Check-Act (PDCA). Essa metodologia é um processo evolutivo que ao passar por cada uma das etapas, promove uma 
análise completa das estratégias e métodos traçados para as questões ambientais, buscando a melhoria contínua do sistema. Esse processo está ilustrado na Figura 1.

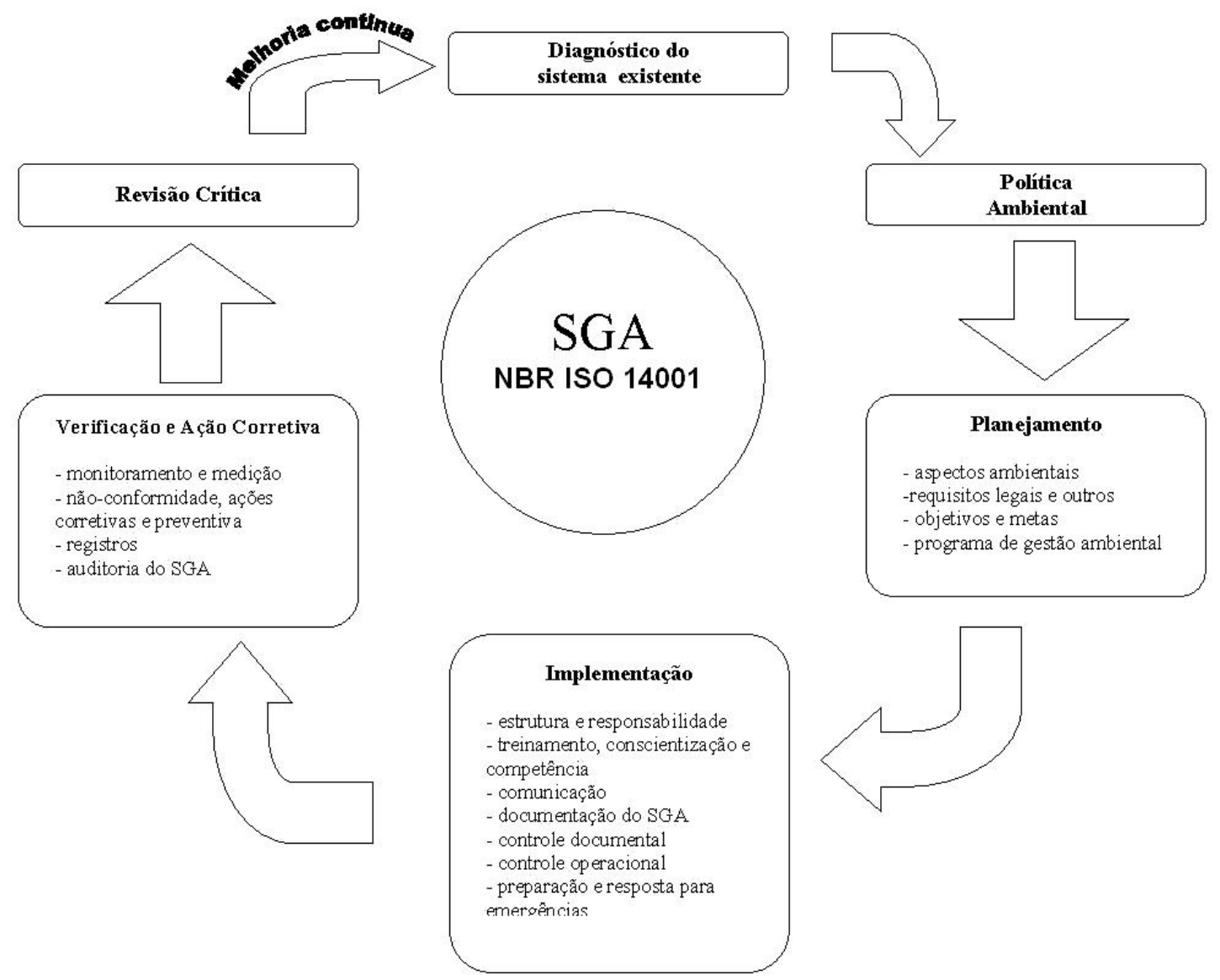

Figura 1 - Ciclo do sistema de gestão ambiental preconizado pela NBR ISO 14001:2004 Fonte: Adaptado de ABNT 2004

Antes de se estabelecer uma política ambiental deve-se realizar uma avaliação inicial dos processos produtivos existentes, mapeando os impactos e agravos ambientais decorrentes desses processos. Conhecendo melhor a interface instituição-ambiente pode-se partir para a elaboração da política ambiental. Segundo Seiffert (2005), a política ambiental deve estar apoiada principalmente no atendimento a legislação vigente, no sistema de melhoria contínua e na prevenção da poluição, entre outros aspectos.

Na fase de planejamento é muito importante a atuação da alta administração para prover ao SGA todos os elementos necessários para a sua implementação. A organização deve estabelecer, implementar e manter objetivos e metas ambientais documentados nas funções e níveis relevantes na organização (Santos, 2007).

Os objetivos e metas devem ser mensuráveis, quando exeqüível, e coerentes com a política ambiental, incluindo-se o comprometimento com a prevenção de poluição, com o atendimento aos requisitos legais e a outros requisitos subscritos pela organização e com a melhoria contínua (ABNT, 2004). Para Araújo (2005), o estabelecimento de uma meta ambiental deve atender sempre a dois princípios básicos: ser exeqüível e ao mesmo tempo significar um desafio. Estas só podem ser estabelecidas após algum tempo de medição de determinado parâmetro, para que possa ser estabelecido um referencial de melhoria. 
Terminada a fase do planejamento, na qual foram identificados todos os aspectos e impactos significativos, requisitos legais e outros requisitos, estabelecidos objetivos e metas, que foram desdobrados em um programa de gestão ambiental, a organização se encontra apta à fase de implementação. Durante essa fase, todos dentro da organização têm que entender com clareza a aplicação da estrutura de responsabilidades.

A organização deve assegurar que qualquer pessoa que, para ela ou em seu nome, realize tarefas que tenham o potencial de causar impacto(s) ambiental(is) significativo(s) identificado(s) pela organização, seja competente com base em formação apropriada, treinamento ou experiência, devendo reter os registros associados (ABNT, 2004).

A comunicação deve ser parte ativa na organização. Dessa forma, deve ser constantemente desenvolvida para a garantia do bom andamento do Sistema de Gestão Ambiental em todos os níveis da organização. Um sistema próprio para gerenciar todos os documentos do SGA deve ser estabelecido, proporcionando a sua organização e manutenção. Isso assegura que possam ser facilmente localizados, periodicamente analisados, revisados quando necessários e aprovados quanto à sua adequação e uso por pessoal responsável (Santos, 2007).

A Norma estabelece a obrigação de se comunicar os critérios e as exigências ambientais as empresas terceirizadas que mantêm algum vínculo de trabalho e cujas atividades relacionadas à organização possuírem aspectos ambientais significativos como: tratamento ou disposição de resíduo final; transporte de produtos perigosos; limpeza e outras operações ambientais relevantes, executadas dentro da unidade; fornecer produtos perigosos, entre outros aspectos (Araújo, 2005).

No item 'Preparação e resposta a emergências' há a exigência de que a organização estabeleça, programe e mantenha procedimentos para identificar potenciais situações de emergência e potenciais acidentes que possam ter impactos sobre o meio ambiente, e como a organização responderá a estes (ABNT, 2004).

$\mathrm{Na}$ fase da verificação, a organização deve: estabelecer, implementar e manter procedimentos para monitorar e medir regularmente as características principais de suas operações que possam ter um impacto ambiental significativo. Os procedimentos devem incluir a documentação de informações para monitorar o desempenho, os controles operacionais pertinentes e a conformidade com os objetivos e metas ambientais da organização(ABNT, 2004).

A organização deve estabelecer, implementar e manter procedimentos para tratar as não-conformidades reais e potenciais, e para executar ações corretivas e preventivas (ABNT, 2004). Ainda na fase da verificação, a Norma prevê que uma organização certificada deve conduzir uma auditoria de acompanhamento ou verificação a cada 6 ou 12 meses.

A necessidade de auditorias internas fica a critério da organização definir sua freqüência. Para definir a freqüência das auditorias pode-se pensar em alguns quesitos como: a natureza da operação a ser auditada a respeito aos impactos ambientais, os resultados do programa de monitoramento e resultados de auditorias anteriores.

Por fim, na fase de análise crítica e melhoria, alta administração da organização deve analisar o sistema da gestão ambiental, em intervalos planejados, para assegurar sua continuidade adequação, pertinência e eficácia. Analises devem incluir a avaliação de oportunidades de melhoria e a necessidade de alterações no sistema da gestão ambiental, inclusive da política ambiental e dos objetivos e metas ambientais (ABNT, 2004).

\section{O Sistema de Gestão Ambiental do Exército Brasileiro (SiGAEB)}

O Exército Brasileiro disponibiliza os documentos normativos gerais sobre seu sistema de gestão ambiental no seu endereço eletrônico principal 
(http://www.exercito.gov.br/03ativid/meioambiente/legislacao.htm). Neste foram encontrados seis documentos completos e três extratos, que apresentam os itens relativos ao meio ambiente que foram inseridos em documentos normativos de outras áreas. Esses documentos são apresentados na Tabela 1.

Tabela 1 - Documentos normativos gerais sobre meio ambiente do Exército Brasileiro

\begin{tabular}{|c|c|c|}
\hline Tipo de documento & Finalidade & $\begin{array}{c}\text { Data de } \\
\text { publicação }\end{array}$ \\
\hline $\begin{array}{l}\text { Portaria } \mathrm{N}^{\circ} 570 \text { do } \\
\text { Comandante do Exército }\end{array}$ & $\begin{array}{l}\text { Política de Gestão Ambiental do Exército } \\
\text { Brasileiro }\end{array}$ & 16 Nov 2001 \\
\hline Portaria $\mathrm{N}^{\circ} 571$ do & Diretriz Estratégica de Gestão Ambiental do & 16 Nov 2001 \\
\hline Comandante do Exército & Exército Brasileiro & 1010002001 \\
\hline Portaria $N^{\circ} 050$ do & Orientação para a Elaboração dos Planos & \\
\hline Comandante do Exército & Básicos de Gestão Ambiental & 11 Jul 2003 \\
\hline $\begin{array}{l}\text { Regulamento Interno dos } \\
\text { Serviços Gerais (RISG) - } \\
\text { extrato }\end{array}$ & $\begin{array}{l}\text { Capítulo IX - Controle ambiental nas } \\
\text { Organizações Militares do Exército } \\
\text { (Atualizado pela Portaria Nº } 816 \text { do } \\
\text { Comandante do Exército) }\end{array}$ & 19 Dez 2003 \\
\hline $\begin{array}{l}\text { Sistema de Instrução Militar } \\
\text { do Exército Brasileiro } \\
\text { (SIMEB) } 2008 \text { - extrato }\end{array}$ & $\begin{array}{l}\text { Item } 3.10 \text { Proteção e instrução sobre meio } \\
\text { ambiente }\end{array}$ & 15 Dez 2007 \\
\hline $\begin{array}{l}\text { Sistema de Instrução Militar } \\
\text { do Exército Brasileiro } \\
\text { (SIMEB) } 2008 \text { - extrato }\end{array}$ & $\begin{array}{l}\text { Item } 3.11 \text { Atividades de instrução em } \\
\text { unidades de conservação }\end{array}$ & 15 Dez 2007 \\
\hline Portaria $N^{\circ} 934$ do & Determina a atualização do Sistema de & \\
\hline Comandante do Exército & $\begin{array}{l}\text { Gestão Ambiental do Exército Brasileiro } \\
\text { Normas para a Promoção da Educação }\end{array}$ & 28 Dez 2007 \\
\hline Portaria $N^{\circ} 014$ do Chefe do & Ambiental nos Estabelecimentos de Ensino & \\
\hline Departamento de Ensino e & e nas Organizações Militares Subordinados & 22 Fev 2008 \\
\hline Pesquisa (DEP) & $\begin{array}{l}\text { e/ou Vinculados ao Departamento de } \\
\text { Ensino e Pesquisa }\end{array}$ & \\
\hline $\begin{array}{l}\text { Portaria } \mathrm{N}^{\circ} 386 \text { do } \\
\text { Comandante do Exército }\end{array}$ & $\begin{array}{l}\text { Aprova as Instruções Gerais para o Sistema } \\
\text { de Gestão Ambiental no Âmbito do } \\
\text { Exército (IG 20-10) e dá outras } \\
\text { providências }\end{array}$ & 18 Jul 2008 \\
\hline
\end{tabular}

O Exército iniciou o processo de implantação do seu SGA publicando a portaria que trouxe ao domínio público a sua Política de Gestão Ambiental (PGAEB). Esse documento contém os objetivos da Força no tocante a questão ambiental. Simultaneamente, a instituição lançou as Diretrizes Estratégicas de Gestão Ambiental do Exército Brasileiro (DEGAEB). Este documento deixa claro, já no item 'Premissas Básicas' que a implementação de um SGA exige procedimentos de conscientização do público interno, em todos os escalões. No mesmo item, afirma que o desenvolvimento das atividades planejadas nos programas de prevenção, preservação, conservação e recuperação ambiental estão condicionados à disponibilidade de recursos orçamentários.

A DEGAEB apresenta a concepção lógica do SGAEB que tem como órgão central o Estado-Maior do Exército (EME), conforme apresentado na Figura 2. 


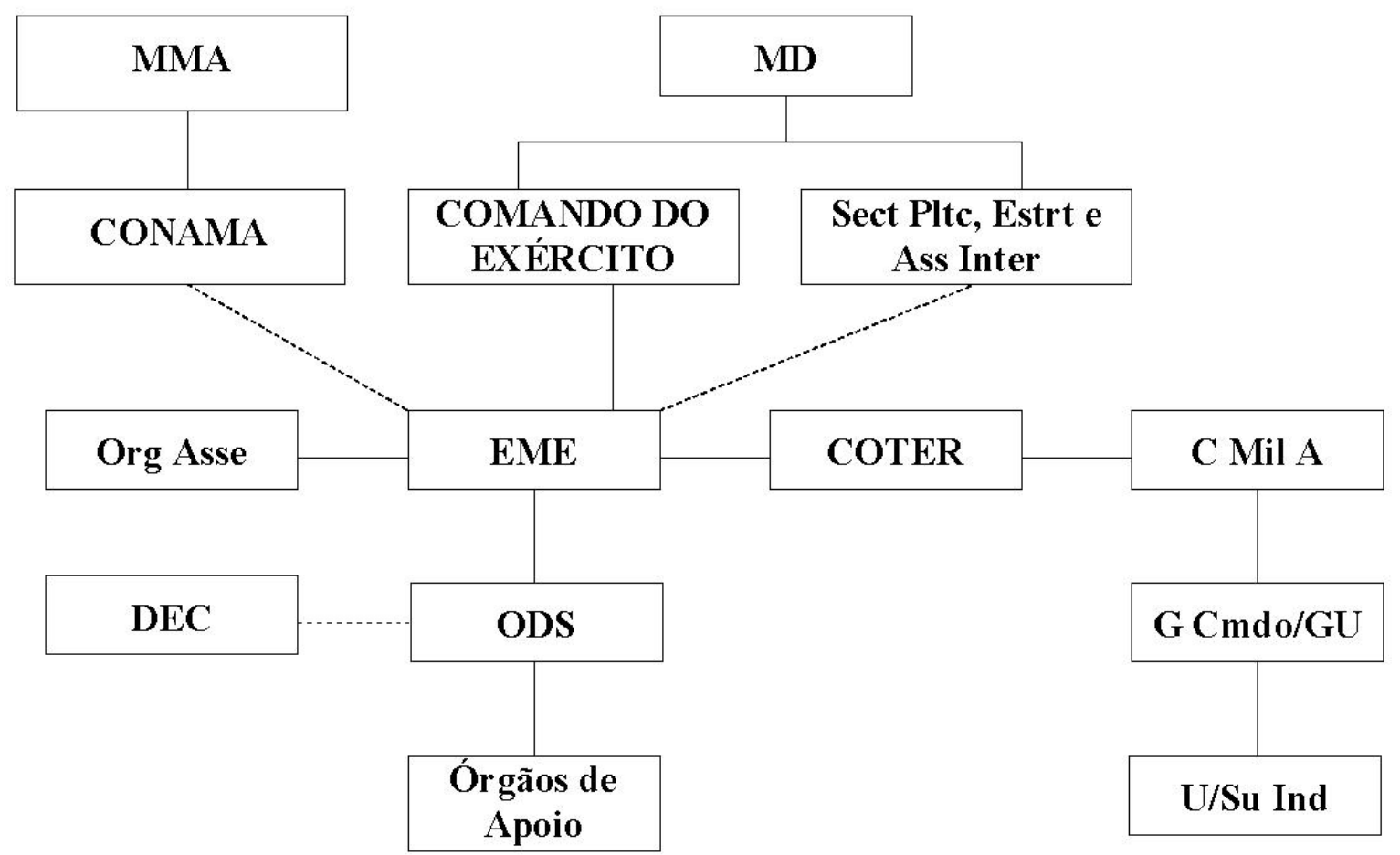

\begin{tabular}{|l|l|l|}
\hline \multicolumn{3}{|c|}{ LEGENDAS } \\
\hline \multirow{-1}{*}{ Subordinação } & $\begin{array}{l}\text { CONAMA - Conselho Nacional do Meio } \\
\text { Ambiente }\end{array}$ & C Mil A - Comando Militar de Área \\
\hline--- Vinculada & $\begin{array}{l}\text { Sect Pltc, Estrt e Ass Inter - Secretaria de } \\
\text { Planejamento Estratégico e Assessoria Interna }\end{array}$ & ODS - Orgãos de Direção Setorial \\
\hline MMA - Ministério do Meio Ambiente & Org Asse - Orgão de Assessoramento & G Cmdo/GU - Grandes Comandos/Guarnição \\
\hline MD -Ministério da Defesa & EME - Estado Maior do Exército & U/SU Ind - Subunidade individual \\
\hline COTER - Comando de Operações Terrestres & DEC - Departamento de Engenharia e Construção \\
\hline
\end{tabular}

Figura 2 - Estrutura do Sistema de Gestão Ambiental do Exército Brasileiro (2008)

O mesmo documento também define o fluxo das ações do SGA: planejamento, execução, coordenação e controle, avaliação (com indicadores já estabelecidos) e a realimentação do sistema.

Em 18 de julho de 2003, o Boletim do Exército $n^{\circ} 29$ publicou a Portaria $n^{\circ} 050$-EME, do dia 11 do mesmo mês, aprovando a Orientação para a Elaboração dos Planos Básicos de Gestão Ambiental. Esse documento teve a finalidade de oferecer subsídios aos ODS para a elaboração dos respectivos PBGAEB.

As orientações da portaria 050-EME sugerem informações e procedimentos a serem adotados por todos aqueles que forem confeccionar os seus respectivos PBGAEB. Essa portaria estabeleceu os seguintes tópicos para os PBGAEB, entre outros: objetivos a atingir, ações a realizar, metas a serem conseguidas, prazos, prioridades para a consecução das metas, indicadores de desempenho, cronograma de atividades, recursos necessários, responsabilidades, atribuições, gerentes, parceiros e outras informações julgadas necessárias.

E ainda, quando for o caso: a avaliação de danos ao meio ambiente que poderão ser causados por determinadas atividades; o desenvolvimento de ações que poderão minimizar possíveis impactos que poderão ocorrer no meio ambiente; os procedimentos a serem adotados nos polígonos de tiro para a destruição de engenhos falhados após a realização do tiro, isolamento e identificação da área; o manejo das áreas de instrução, alternando os locais das instruções para evitar ou minimizar o dano ambiental causado pelo uso excessivo de determinado local; os óbices com falta de recursos, dificuldades de controle de áreas, inclusão 
de campo de instrução em Área de Proteção Ambiental (APA); as atividades e empreendimentos submetidos a licenciamento ambiental; e as ações de gestão realizadas (BRASIL, 2003).

Como sugestão de programas de gestão ambiental a serem elaborados, essas orientações apresentaram os seguintes exemplos: Educação Ambiental; Capacitação de Recursos Humanos na Área Ambiental; Recuperação de Áreas Degradadas; Gerenciamento de Resíduos de Obras de Engenharia; Ocupação e Uso dos Campos de Instrução; Ocupação e Uso do Campo de Provas da Marambaia; Gerenciamento dos Resíduos Sólidos Produzidos em Estabelecimentos de Saúde; e Processamento de Afluentes Resultantes da Fosfatização de Armamento (Campos, 2003).

Com a portaria 050-EME ficou estabelecido, pela primeira vez, a obrigatoriedade do envio dos planos de gestão ambiental (PGA) dos ODS ao EME para fins de avaliação e consolidação, a partir de 2004. A portaria também estabeleceu que a remessa dos PGAs deveria ocorrer, regularmente, até o dia 15 de março de cada ano (Campos, 2003).

Ainda em 2003, o Regulamento Interno dos Serviços Gerais (RISG) foi alterado com a inclusão do capítulo IX (Do Controle Ambiental) e outros artigos referentes a cuidados com o meio ambiente distribuído pelas demais seções desse regulamento. O conteúdo do capítulo incluído define procedimentos a serem adotados para o controle ambiental a ser executado nas OM do Exército Brasileiro, observando as orientações contidas na legislação federal, estadual e municipal (Brasil, 2004).

Entre o ano de 2004 e o mês de dezembro de 2007 não foi produzido qualquer documento normativos relativo ao SiGAEB. Em 15 de dezembro de 2007, é divulgado pelo COTer o planejamento do Sistema de Instrução Militar do Exército Brasileiro (SIMEB) para o ano de 2008 que apresentou a inclusão dos itens 3.10 e 3.11, Proteção e instrução sobre meio ambiente e Atividades de instrução em unidades de conservação, respectivamente.

O Item 3.10 (Proteção e Instrução sobre Meio Ambiente) determina que os responsáveis pelas atividades nas áreas de instrução deverão orientar todos os participantes sobre a conservação do meio ambiente, principalmente no tocante à flora, à fauna e aos recursos hídricos (cursos d‘água, lagos e lagoas) e fiscalizar o rigoroso cumprimento da legislação ambiental em vigor. $\mathrm{E}$ ainda, proíbe o uso de animais silvestres e orienta a não derrubada de árvores nativas nas atividades de instrução.

Já o Item 3.11 (Atividades de Instrução em Unidades de Conservação) faz referencia a necessidade da participação de funcionários da Polícia Federal e do IBAMA quando houver da realização de instruções ou exercícios de tropa em unidade de conservação, ficando a direção de instrução das OM responsável pela observância dessa peculiaridade.

Em 20 de dezembro de 2007, o Comandante do Exército atualizou o SIGAEB por meio da Portaria 934. Essa Portaria determinou, em seu Art. $2^{\circ}$, que o EME inserisse a Política de Gestão Ambiental do Exército Brasileiro na Política Militar Terrestre da Instituição para um gerenciamento efetivo, que assegurasse o fiel cumprimento da legislação ambiental e promovesse a convivência harmônica da Força Terrestre com o Ecossistema (Brasil, 2007).

A Portaria 934 determinou também a centralização da execução das ações voltadas ao meio ambiente no Departamento de Engenharia e Construção (DEC), ODS supervisor e técnico, para o cumprimento da legislação e a solução dos problemas ambientais que venham a ser identificados pelas OM (Brasil, 2007).

Consciente da potencialidade do sistema de ensino do Exército, o Chefe do Departamento de Ensino e Pesquisa (DEP) do Exército publicou a Portaria No 014 que trata sobre as Normas para a Promoção da Educação Ambiental nos Estabelecimentos de Ensino e nas Organizações Militares Subordinados e/ou Vinculados ao Departamento de Ensino e Pesquisa. 
Esta portaria prescreve que "a abordagem da educação ambiental buscará, sempre, a absorção de valores ambientais e será desenvolvida em três enfoques: naturalista, jurídico e sócio-ambiental [...]” (Brasil, 2008a). Além disso, torna obrigatória a abordagem da educação ambiental em todos os cursos e estágios dos Estabelecimentos de Ensino e OM Subordinados e/ou vinculados às diretorias do DEP.

No mesmo ano, o Comandante do Exército aprovou, no dia 9 de junho, as Instruções Gerais (IG) para o Sistema de Gestão Ambiental no Âmbito do Exército por meio da Portaria $\mathrm{N}^{\circ}$ 386. Esta IG atribui ao EME a responsabilidade pela proposição das atualizações da legislação ambiental e ao Departamento de Engenharia de Construção (DEC) a confecção de Instruções Reguladoras e consultoria técnica dentro do SiGAEB. (Brasil, 2008b).

A Portaria 386 foi o primeiro documento que apresentou explicitamente os integrantes do SiGAEB: o EME, os ODS, os Cmdo Mil A, as RM, as Grandes Unidades, as Organizações Militares e os militares. Outra característica deste documento é a divisão da gestão ambiental do Exército em campos específicos que, no seu conjunto, abrangem todas as atividades desenvolvidas pela Instituição.

\section{Analisando a SiGAEB frente as etapas propostas pela NBR ISO 14001}

\section{Etapa 1 - Diagnóstico e compromisso com uma política ambiental}

Como mencionado anteriormente, é recomendável que se realize um diagnóstico prévio da situação ambiental da instituição antes da publicação da política ambiental. No entanto, não foram obtidas evidências da realização de diagnóstico prévio a publicação da PGAEB. Com relação ao comprometimento de seus integrantes com a política ambiental estabelecida, Lima (2003) e Porto (2004) observaram que a divulgação ao público interno foi mínima, não atingindo a "ponta da linha”. A análise cronológica dos documentos estudados sugere que a questão ambiental não recebeu a atenção adequada, uma vez que se constatou um hiato de sete anos entre a publicação da Política de Gestão Ambiental do Exército Brasileiro (2001) e a publicação das Instruções Gerais para o Sistema de Gestão Ambiental no Âmbito do Exército (2008), ambas consideradas pedras fundamentais à estruturação de um SGA

\section{Etapa 2 - Planejamento}

Nessa fase a instituição deveria ter considerado os aspectos ambientais, os requisitos legais e o estabelecimento de objetivos, metas e programas. No entanto, o SiGAEB é instituído em 2001 pela Diretriz Estratégica de Gestão Ambiental do Exército Brasileiro, na mesma data da publicação da política ambiental da Instituição, com objetivos ainda difusos e abrangentes demais, sem metas ou prazos e sem especificação dos executores, como pode ser observado no trecho abaixo:

\footnotetext{
$[\ldots]$

- Incutir, no público interno, a mentalidade de prevenção, preservação, conservação, melhoria e recuperação do meio ambiente, seja por intermédio de campanhas, seja valendo-se de diretrizes expedidas por ocasião da realização de atividades e empreendimentos militares.

- Classificar as atividades e empreendimentos, segundo a legislação de meio ambiente em vigor, solicitando, quando necessário, o Estudo do Impacto Ambiental (EIA) e o Relatório de Impacto sobre o Meio Ambiente (RIMA).

- Fiscalizar e controlar os recursos ambientais expostos às ações das atividades e empreendimentos.

- Praticar a preservação ou a conservação ambientais, desenvolvendo programas e projetos, racionalizando o uso dos recursos ambientais disponíveis e incluindo a
} 
proteção e a preservação do meio ambiente como aspectos críticos no planejamento e na execução das atividades e dos empreendimentos militares. (Brasil, 2001b)

Apesar da diversidade de ecossistemas em que as organizações militares estão inseridas, as atividades desenvolvidas por elas são, em sua maior parte, comum a todas. Isso permitiria uma definição de prioridade na implementação das ações de gestão, o que não foi observado nos documentos analisados. Com relação aos objetivos e às metas, Fogliatti e Goulard (2004) afirmam que os objetivos podem desdobrar-se em metas, e para cada meta devem ser elaborados planos de ação que operacionalizem sua consecução. Os mesmos autores ainda sinalizam que esses planos de ação deverão detalhar os meios (recursos), os responsáveis e os prazos.

Com relação aos recursos físicos e financeiros para o SiGAEB a mesma diretriz define que "O planejamento dos programas de prevenção, preservação, conservação e recuperação ambiental deverá discriminar o montante de recursos necessários às suas execuções, ficando o desenvolvimento condicionado à disponibilidade de recursos orçamentários ou daqueles que forem alocados por órgãos públicos ou privados.", e que a estrutura organizacional para o SiGAEB utilizará "a estrutura do Exército, valendo-se de recursos de toda ordem humanos, físicos, financeiros e tecnológicos”.

Esses trechos sugerem que os planejadores do SiGAEB realizaram esse trabalho sob uma ou ambas as condições a seguir: "sob pressão" de prazos visivelmente insuficientes, para que a Instituição pudesse divulgar que desenvolve um SGA, coerente com a política de manutenção da imagem institucional; e/ou na ausência de pessoal capacitado ao planejamento de um SGA e que conhecesse também as peculiaridades do Exército Brasileiro, para que fosse elaborado um sistema customizado à Instituição.

\section{Etapa 3 - Implementação e operação}

Neste aspecto o SiGAEB se aproxima das recomendações da Norma, pois a figura 2 deixa claro que as funções e responsabilidades ambientais não são vistas como confinadas à função da gestão ambiental, mas estão afetas a todas as áreas de Instituição. Porém, devido à dimensão do Exército Brasileiro, essa tranversalidade de funções e responsabilidades com a gestão ambiental só se torna efetiva na medida em que, na micro-estrutura da organização militar (OM), isso também se viabilize. Lima (2003) e Porto (2004) nos contextos por eles analisados sinalizaram que essa dinâmica não ocorria na prática.

A Norma recomenda que a Instituição identifique a conscientização, o conhecimento, a compreensão e as habilidades necessárias a qualquer indivíduo com responsabilidade e autoridade para realizar tarefas em seu nome (ABNT, 2004). Porém, apesar de constar na política ambiental da instituição que "A educação ambiental deverá ser promovida pelo Sistema de Ensino do Exército e pelo Sistema de Instrução Militar do Exército Brasileiro (SIMEB), com a finalidade de desenvolver, junto ao público interno, a mentalidade de comprometimento com a gestão ambiental." o Exército demorou seis anos para incluir a questão ambiental no seu Sistema de Instrução Militar e sete anos para publicar as Normas para a Promoção da Educação Ambiental nos Estabelecimentos de Ensino e nas Organizações Militares Subordinados e/ou Vinculados ao Departamento de Ensino e Pesquisa. Esse hiato cronológico reflete a dificuldade operacional da Instituição na questão da comunicação interna e na coordenação de esforços entre os órgãos de direção setorial da Instituição.

Antes da publicação desses documentos, outros textos fizeram referência a esse aspecto como objetivos específicos, porém de forma bastante superficial como pode ser verificado a seguir: "Formar recursos humanos especializados em gestão ambiental, com a finalidade de elaborar estudos e decorrentes relatórios de impactos ambientais, referentes aos empreendimentos e às atividades a serem realizados pelo Exército” (Brasil, 2001a); 
"Capacitação de recursos humanos, de acordo com as necessidades da Força" (Brasil, 2001); "Determinar ao Departamento de Ensino e Pesquisa que incentive e promova a educação ambiental, valendo-se do Sistema de Ensino do Exército Brasileiro” (Brasil, 2007).

A comunicação interna é importante para assegurar a eficaz implementação do sistema da gestão ambiental, e é recomendável que as organizações programem um procedimento para receber, documentar e responder às comunicações das partes interessadas (ABNT, 2004). Neste aspecto não se observou qualquer canal de comunicação específico à área de gestão ambiental, exceto a orientação da busca de orientações técnicas no DEC divulgada em 2008 na portaria 386, porém nenhuma estrutura virtual ou física foi criada para este fim.

No tocante a documentação, o SiGAEB está de acordo com as Normas pois os documentos existentes apresentam um nível de detalhamento suficiente para descrever os elementos principais do sistema da gestão ambiental e sua interação (Figura 2), embora no aspecto metas e prazos ainda se encontram com bastante superficialidade. Apenas um tipo de documento recomendado pela norma não foi observado durante o estudo: os planos locais de emergência.

O Controle operacional e de documentação do SiGAEB restringiu-se inicialmente à aprovação dos Planos Básicos de Gestão ambiental dos ODS pelo EME, como pode ser observado no trecho a seguir: "Baseados na DEGAEB, os ODS que desenvolverem atividades ou empreendimentos passíveis de provocarem danos ou degradação ao meio ambiente, remeterão ao EME, até 15 de março, as propostas dos respectivos PBGAEB para avaliação e consolidação." (Brasil, 2001B). Esse texto ainda restringe a orientação para elaboração dos planos básicos de gestão somente aos ODS que desenvolvam atividades potencialmente danosas ao meio ambiente, negligenciando os aspectos de preservação, conservação e recuperação de áreas degradadas, definidos como objetivos do sistema pela própria DEGAEB.

Recentemente, em 2008, a portaria 386 trouxe os seguintes conteúdos: “Os ODS, os $C$ Mil A e as RM são os responsáveis pelo planejamento, coordenação, controle, fiscalização, avaliação das ações de gestão ambiental, bem como pela supervisão do cumprimento da legislação, dentro de suas áreas" e "O Departamento de Engenharia e Construção (DEC) será o órgão supervisor das ações básicas e de consultoria técnica para as questões ambientais do Exército, a fim de se buscar a otimização das ações ambientais” (Brasil, 2008b). O texto sugere que o EME não estava capacitado a suprir as necessidades técnicas sobre as diversas vertentes necessárias a uma adequada gestão ambiental, demonstrando claramente uma expectativa de que o DEC consiga atender essas necessidades e orientar a execução do SiGAEB.

Outro aspecto discutido pela Norma, mas que não foi observado nos documentos normativos do SiGAEB foi a preparação e respostas a emergências. Mesmo que alguma organização militar, isoladamente, tenha desenvolvido tal tópico em seu planejamento, esse tema não poderia deixar de ser abordado nos documentos normativos gerais.

\section{Etapa 4- Verificação e ação corretiva}

Qualquer instituição que desenvolve um SGA deve quantificar a qualidade da sua relação com o ambiente por meio de monitoramentos ambientais e, se necessário, biológicos. Por exemplo, as características relativas ao monitoramento e medição de descarga de esgoto poderiam incluir demanda biológica e química por oxigênio, temperatura e acidez (ABNT, 2004).

O monitoramento ambiental pode ser definido como um processo de coleta de dados, estudo e acompanhamento contínuo e sistemático das variáveis ambientais, visando compreender as condições ecológicas atuais e estabelecer previsões de riscos futuros para as 
matrizes ecológicas avaliadas (USEPA, 2009). No entanto, as variáveis sociais, econômicas e institucionais também devem ser consideradas, por exercerem influências sobre o meio ambiente. Desta forma, esse procedimento subsidia medidas de planejamento, controle, recuperação, preservação e conservação do ambiente de estudo, bem como auxilia na definição das políticas sócio-ambientais.

Alguns documentos do SiGAEB fazem menção à estudos de impacto ambiental (EIA) e à relatórios de impacto ambiental (RIMA): "Classificar as atividades e empreendimentos, segundo a legislação de meio ambiente em vigor, solicitando, quando necessário, o Estudo do Impacto Ambiental (EIA) e o Relatório de Impacto sobre o Meio Ambiente (RIMA)" - Nas Orientações Gerais das DEGAEB; "Permitir a identificação da necessidade de realização prévia do estudo do impacto ambiental (EIA) e do relatório de impacto sobre o meio ambiente (RIMA), em relação às atividades e aos empreendimentos militares, objetivando o necessário respaldo legal para suas execuções.” Nos Objetivos da Portaria 014 de 2008 do chefe do DEP e "Enfatizar, no estudo da Lei $n^{\circ}$ 9.605, de 12 Fev 98, os aspectos jurídicos relacionados e a classificação das atividades e dos empreendimentos militares. Identificar, segundo a legislação de meio ambiente em vigor, as situações em que se faz necessária a realização de EIA e/ou de RIMA” - Nas orientações para implementação da educação ambiental nos cursos de aperfeiçoamentos militares, do mesmo documento.

Contudo, a preocupação das autoridades militares parece ser apenas o atendimento aos requisitos legais à realização de obras e outras atividades esporádicas. Além da limitação destes objetivos, as ferramentas mencionadas também não são mais adequadas ao acompanhamento contínuo e sistemático das diversas intervenções do Exército no ambiente, pontualmente e ao longo do tempo. Tendo em vista a amplitude das atividades desenvolvidas pelo Exército, o emprego de uma bateria de bioindicadores, como recomenda Arias et al.,(2007), abrangendo distintos níveis de organização biológica possibilitaria o conhecimento da magnitude da influência das atividades militares nos ecossistemas em questão.

Ainda nesta fase, a Norma recomenda a realização de auditorias internas que podem ser realizadas por pessoas que trabalhem para a própria organização ou por pessoas externas. Em ambos os casos, as pessoas que realizam a auditoria devem possuir a capacitação adequada e atuar de forma imparcial e objetiva (ABNT, 2004). Neste aspecto, não se observou nenhuma menção à realização de auditorias da forma como é recomendada pela Norma, porém a cultura militar e a estrutura do Exército Brasileiro fazem com que os chefes militares realizem inspeções regulares (em média três vezes ao ano) nas suas organizações militares subordinadas. Neste caso, o auditor sempre possui uma ascendência hierárquica ao auditado, mas nem sempre possui a capacitação adequada à verificação dos procedimentos de gestão ambiental.

Quanto ao controle de registro do SiGAEB, A Portaria do Comandante do Exército número 386 de 2008 que publicou as instruções gerais para o sistema de gestão ambiental no âmbito do Exército atribui aos ODS, C Mil A e RM a responsabilidade pelo planejamento, coordenação, controle, fiscalização, avaliação das ações de gestão ambiental, bem como pela supervisão do cumprimento da legislação, dentro de suas áreas.

$\mathrm{E}$ ainda, o mesmo documento orienta que: "Para o desenvolvimento e permanente aprimoramento, o SIGAEB necessita receber a descrição de fatos e situações vividas, que devem ser encaminhadas ao DEC para consolidação e difusão.”, e que:”O DEC deve realizar continuados estudos no sentido de aprimorar o SIGAEB, submetendo as propostas à apreciação do EME.” Esses trechos revelam que a instituição utiliza-se de métodos empíricos bem como de estudos técnicos para fundamentar as atualizações e melhorias, entretanto, o foco e a profundidade destes vão depender da formação dos recursos humanos diretamente ligados à esse processo. 


\section{Etapa 5 - Análise crítica e melhoria}

A Norma recomenda que a análise pela alta administração cubra o escopo do sistema da gestão ambiental, embora nem todos os elementos do sistema da gestão ambiental necessitem ser analisados de uma só vez, podendo o processo de análise se estender por um período de tempo (ABNT, 2004). Esse aspecto parece ter sido considerado nas ações do Exército, uma vez que alguns elementos do SiGAEB (DEC e DEP) têm implementado melhorias à versão inicial do sistema.

Entretanto, não se observou registro ou citação a respeito da realização de algum processo de análise crítica do SiGAEB, apesar de constar nas DEGAEB a seguinte diretriz: "A realimentação do sistema será feita por intermédio de relatórios elaborados pelos Órgãos envolvidos e remetidos ao EME, pelo canal de comando.”. Neste sentido, mesmo considerando essa forma de realizar a análise, os intervalos de tempo entre o início do SiGAEB e a implementação das melhorias ainda pode ser considerado bastante grande. Tal fato sugere que esse é um processo não sistemático, e provavelmente, não depende apenas de fatores internos do sistema, mas de decisões estratégicas e políticas relacionadas com a avaliação e disponibilização de dados que permitam a visibilidade da atuação da instituição na área ambiental.

\section{CONSIDERAÇÕES FINAIS}

Da mesma forma que a maioria das instituições civis que implementam um SGA, o foco do SiGAEB está no cumprimento dos requisitos legais e a busca do equilíbrio entre a preservação do meio ambiente e a manutenção de suas atividades. O principal produto das atividades militares em tempos e paz é a manutenção dos níveis de treinamento de tropas, voltado para a manutenção da soberania e da integridade nacional. Uma vez que grandes partes dos treinamentos militares são realizados em áreas verdes, são necessários planejamento e implementação de estratégias para o acompanhamento contínuo e sistemático da influência das atividades militares nos ecossistemas, e ainda, para a recuperação e conservação ambiental, bem como auxilio na definição das políticas sócio-ambientais.

O presente estudo indica que o SiGAEB parece ter sido planejado de acordo com as fases preconizadas pela NBR ISO 14001, ainda que uma série de aspectos do seu planejamento, implementação e análise crítica estejam ausentes. Indica também que em seu estágio atual, a preocupação das autoridades militares está muitas vezes restrita ao atendimento aos requisitos legais à realização de obras e outras atividades esporádicas, distanciando-se de uma concreta operação do Sistema tal como preconizado na figura 2.

Por outro lado, vimos que a cultura militar e a estrutura do Exército Brasileiro trazem elementos que podem favorecer a operação do sistema da gestão ambiental, tais como: 1. a prática da inspeção regular das chefias militares nas suas organizações subordinadas, que pode servir para a futura capacitação para as auditorias recomendadas pela Norma; 2. a formação, treinamento e experiência para realizar registros militares, que pode ser aplicada ao registro de tarefas que tenham o potencial de causar impacto(s) ambiental(is) significativo(s) identificado(s) pela organização; 3. as atividades de rotina das organizações militares que preconizam cuidados para não deixar vestígios no ambiente, que favorecem por exemplo o cumprimento dos planos de gestão ambiental no tocante ao destino de resíduos; etc.

A partir da viabilização do SiGAEB, a integração de práticas ambientais no setor militar no Brasil pode ter resultados como os registrados para outros países, com atividades como: tratamento dos resíduos e águas residuais, gestão da utilização e descontaminação dos solos, conservação dos ecossistemas e educação ambiental, etc. Para tal, é necessário superar 
também a precariedade atual da comunicação interna sobre o área de gestão ambiental, no interior instituição.

A Norma preconiza que as organizações programem um procedimento para receber, documentar e responder às comunicações, a clareza nas atribuições e o envolvimento de todos os membros da organização ligados direta e indiretamente ao SiGAEB. A comunicação deve ser parte ativa na organização, e para assegurá-la, canais específicos devem ser criados para abrangência da divulgação ao público interno ou "ponta da linha”.

Neste sentido, a presente análise dá início a uma pesquisa mais abrangente que envolve investigar os conhecimentos e práticas relativos ao SiGAEB em nível nacional, buscando contribuir ao entendimento da atual situação de implementação da gestão ambiental e de seus principais desafios para a efetividade das contribuições do Exército à problemática sócio-ambiental.

\section{REFERÊNCIAS}

Abreu, R.P. (2006) O Uso Sustentável dos Campos de Instrução do Exército Brasileiro, nos Exercícios e Manobras, sem Afetar a Operacionalidade. 2006. Trabalho de Conclusão de Curso não publicado - Gestão Ambiental, Universidade Presidente Antônio Carlos - INIPAC, 53p.

Andrade Júnior, H. (2005) Limites e desafios aos militares brasileiros em relação à questão ambiental. Tese de doutorado em Saúde Pública não publicado. ENSP/FIOCRUZ.

Araújo, M. G. (2005) Sistema de Gestão Ambiental ISO 14001/04 Comentada. Rio de Janeiro: GVC.

Arias, A.R.L.; Buss, D.F.; Alburquerque, C.; Inácio, A.F.; Freire, M.M.; Egler, M. et al. (2007) Utilização de bioindicadores na avaliação de impacto e no monitoramento da contaminação de rios e córregos por agrotóxicos. Ciênc. saúde coletiva; 12(1): 61-72.

Associação Brasileira de Normas Técnicas - ABNT (2004). NBR ISO 14001 - Sistemas de Gestão Ambiental - Especificações e Diretrizes para Uso. Rio de Janeiro.

Brasil. (2008a) Exército Brasileiro. Portaria no 014 Chefe do Departamento de Ensino e Pesquisa, de 8 de fevereiro de 2008. Aprova as Normas para a Promoção da Educação Ambiental nos Estabelecimentos de Ensino e nas Organizações Militares Subordinados e/ou Vinculados ao Departamento de Ensino e Pesquisa. Boletim do Exército, Brasília, DF, n. 08, 22 fev 2008.

Brasil. (2003) Exército Brasileiro. Portaria no 050 do Comandante do Exército, de 11 de julho de 2003. Aprova a Orientação para a Elaboração dos Planos Básicos de Gestão Ambiental. Boletim do Exército, Brasília, DF, n. 29, 18 jul 2003.

Brasil. (2008b) Exército Brasileiro. Portaria ${ }^{\circ} 386$ do Comandante do Exército, de 9 de junho de 2008. Aprova as Instruções Gerais para o Sistema de Gestão Ambiental no Âmbito do Exército (IG 20-10) e dá outras providências. Boletim do Exército, Brasília, DF, n. 29, 18 jul 2008. 
Brasil. (2001a) Exército Brasileiro. Portaria $n^{0} 570$ do Comandante do Exército, de 6 de novembro de 2001. Aprova a Política de Gestão Ambiental do Exército Brasileiro. Boletim do Exército, Brasília, DF, n. 46, 16 nov 2001.

Brasil. (2001b) Exército Brasileiro. Portaria $n^{0} 571$ do Comandante do Exército, de 6 de novembro de 2001. Aprova a Diretriz Estratégica de Gestão Ambiental do Exército Brasileiro. Boletim do Exército, Brasília, DF, n. 46, 16 nov 2001.

Brasil. (2007) Exército Brasileiro. Portaria no 934 do Comandante do Exército, de 20 de dezembro de 2001. Determina a atualização do Sistema de Gestão Ambiental do Exército Brasileiro. Boletim do Exército, Brasília, DF, n. 52, 28 dez 2007.

Brasil. (2004) Exército Brasileiro. Regulamento Interno dos Serviços Gerais. Brasília: EGGCF.

Cagnin, H. C. Fatores Relevantes na Implementação de um Sistema de Gestão Ambiental com Base na Norma ISO 14001. Florianópolis, 2000. Dissertação de Mestrado não publicada. PPGEP - Universidade Federal de santa Catarina - UFSC.

Campos, J.C.P. A gestão ambiental no Exército Brasileiro e a sua compatibilização com o adestramento da Força. Trabalho de Conclusão de Curso não publicado(Curso de Política, Estratégia e Alta Administração do Exército), Escola de Comando e Estado-Maior do Exército, Rio de Janeiro, 2003. 74 p.

Defense Environmental Network \& Information Exchange - DENIX. (2007) Environmental Management Systems. Annual Report to Congress. https://www.denix.osd.mil/portal/page/portal/denix/environment/ARC/FY2007 • [accessed: 21/09/2008].

Dias, G.L.S.; Aguirre, B.M.B. (1992) Crise político-econômica: as raízes do impasse. Estudos Avançados, São Paulo, v. 6, n. 14. Available from $<$ http://www.scielo.br/scielo.php?script=sci_arttext\&pid=S010340141992000100006\&lng=en \&nrm=iso>. access on 07 Mar. 2010.

Diersing, N.E.; Shaw, R.B.; Tazik, D.J. (1992)- US-army land condition-trend analysis program. Environmental Science v.16, n.3: p.405-414

Espanha. (2008) Ministério da Defesa. Dirección General de Infraestructura. Plan General de Medio Ambiente. Disponivel em: http://www.mde.es/contenido.jsp?id_nodo=4755\&\&\&keyword=\&auditoria=F\#4 . Acesso em: 05 de novembro de 2008.

Fogliatti, MC; Goulard, S. F. B. (2004) Avaliação de impactos ambientais. São Paulo: Interciência.

Wang G, Gertner G, Anderson A, Howard H (2009) Simulating Spatial Pattern and Dynamics of Military Training Impacts for Allocation of Land Repair Using Images. Environmental Management v.44, n. 4, p 810-823 
Land Force Command, Department Of National Defence and The Canadian Forces (2008). Environmental Management System e Land Force Command. Disponivel em: http://www.army.forces.gc.ca/lf/english/1_8_3_5.asp Acesso em: 05 de novembro de 2008.

Laville, C.; Dionne, J. (1999) A construção do saber. Belo Horizonte: UFMG, 340 p.

Lederer SE. (1997) Use of an environmental management system at an operating military facility. In: Annual Joint Service Pollution Prevention Conference. Air Force Center for Environmental Excellence.

Lima, W. N. F.(2003) Influência da Legislação Ambiental na formação e adestramento de tropas do Exército Brasileiro. Dissertação de Mestrado não publicada - Curso de Altos Estudos Militares - Escola de Comando e Estado-Maior do Exército, Rio de Janeiro.

Luigi, G. A (1999) Nova Senha para Abrir Mercados. Rev. Rumos do Desenvolvimento, v.23, $\mathrm{n}^{\circ} 157$, p.16 -19.

Maimon, D. (1994) Eco-estratégia nas empresas brasileiras: realidade ou discurso? Revista de Administração de Empresas, São Paulo, v. 34, n. 4, p. 119-130

Michael C. Quist, Philip A. Fay, Christopher S. Guy, Alan K. Knapp, Brett N. Rubenstein (2003) Military training effects on terrestrial and aquatic communities on a grassland military installation. Ecological Applications: v.13, n.2, p. 432-442.

North Atlantic Treaty Organisation - NATO. (2000) Environmental management systems in the military sector. North Atlantic Treaty Organisation, Committee on the Challenges of Modern Society; 2000.

Patterson M. (1999) Optimisation techniques for remedial system performance utilizing the Air Combat Command (ACC) Site Closure Guidance Manual (SCGM). In: Francis D, Blevins T, editors. Environmental training symposium protecting America's natural and national security. Course 093. Virginia, Proceedings of the air combat command environmental leadership council held in St. Louis, Missouri (United States), 1e5 February 1999. The United States Air Force; p. 77-95.

Porto, A. A. (2004) A gestão sustentável dos recursos naturais nos Campos de Instrução do Exército Brasileiro. Dissertação de Mestrado não publicada- Curso de Altos Estudos Militares - Escola de Comando e Estado-Maior do Exército, Rio de Janeiro.

Portugal. (2008) Ministério da Defesa Nacional. Defesa e ambiente. Disponível em: http://www.mdn.gov.pt/mdn/pt/mdn/organograma/dgie/ambiente/ Acesso em: 05 de novembro de 2008.

Roberts, K.H.; Stout, S.K.; Halpern, J.J. (1994), Decision Dynamics in Two High Reliability Military Organizations Management Science, v.40, n.5, p.614-624

Santos, N.C.R. (2007) A implementação da NBR ISO 14OO1:2004 em organizações: um estudo multicaso. Dissertação de Mestrado em Engenharia de Produção não publicada. Universidade Federal de Santa Maria, RS, 151p. 
Seiffert, M. E. B. ISO 14001: sistemas de gestão ambiental. São Paulo: Atlas, 2005.

Sorrentino, M; Trajber, R; Mendonça, P; Ferraro Jr., LA. (2005) Educação Ambiental como política pública. Educação e Pesquisa, São Paulo, v. 31, n. 2, p. 285-299

Souza, R. S. Entendendo a Questão Ambiental: Temas de Economia, Política e Gestão do Meio Ambiente. Santa Cruz do Sul: EDUNISC, 2000

United States Environmental Protection Agency - USEPA (2008). Environmental Management Systems (EMS). Disponível em: http://www.epa.gov/ems/index.html. Acesso em: 08 de setembro de 2008

United States Environmental Protection Agency - USEPA (2009). Environmental Monitoring \& Assessment Program. Disponível em: http://www.epa.gov/emap/ . Acesso em: 28 de janeiro de 2009.

United States Air Force - USAF (1995). US air force handbook to environmental quality. Washington, DC: Directorate of Environment HQ USAF/CEV, Department of the Air Force, United States of America; 1995.

United States Department of Defense; Swedish Armed Forces (1999). Environmental Considerations in the Systems Acquisition Process - A Handbook for Program Managers. A joint publication of the Swedish Armed Forces and the Department of Defense of the United States of America. Washington, USA; 1999.

United States Army Environmental Command - USAEC (2007). Environmental Management System: Commanders Guide. U.S. Army. 